\title{
Pengajaran Materi Perkembangan Manusia Untuk Guru-Guru Sekolah Kristen
}

\author{
Heliany Kiswantomo ${ }^{\# 1}$, Jane Savitri" ${ }^{* 2}$ \\ ${ }^{\#}$ Fakultas Psikologi, Universitas Kristen Maranatha \\ Jl Prof. Drg. Surya Sumantri 65 Bandung \\ ${ }^{1}$ helianyk@gmail.com \\ 2janesavitri73@gmail.com
}

\begin{abstract}
Abstrak - Guru sebagai salah satu komponen penting dalam sistem pendidikan, perlu meningkatkan kompetensinya. Salah satu lembaga yang peduli terhadap peningkatan kompetensi guru adalah ACSI (Association of Christian School International). ACSI bekerja sama dengan Dosen Fakultas Psikologi Universitas Kristen Maranatha, menyelenggarakan pengajaran Perkembangan manusia, untuk guru-guru Kristen di Indonesia. Tujuan pengajaran ini adalah meningkatkan pemahaman guru mengenai karakteristik perkembangan manusia, mencakup materi perkembangan fisik-motorik, kognitif, moral, spiritual, memory, belajar, motivasi dan perkembangan anak usia dini. Diharapkan materi ini dapat membantu guru saat menjalankan perannya mendidik siswa. Metode yang digunakan dalam pengajaran ini adalah dengan menggunakan 8 video pembelajaran yang telah disiapkan oleh narasumber. Kegiatan ini diikuti oleh 26 guru yang berasal dari beberapa kota di Indonesia. Peserta harus menyimak video tersebut terlebih dahulu selama tiga minggu. Setelah itu, mereka harus mengerjakan tugas-tugas yang diberikan. Pada tanggal 22 dan 29 Mei 2021, diadakan pertemuan tatap muka daring dengan media zoom, antara peserta dan narasumber, dengan kegiatan tanya jawab dan diskusi mengenai materi yang telah disajikan. Setelah pengajaran dilakukan, dilakukan evaluasi melalui penyebaran kuesioner. Hasil evaluasi menyatakan bahwa pemahaman mengenai materi perkembangan manusia mengalami peningkatan. Evaluasi pelaksanaan pengajaran ini juga sebagian besar dinilai sangat baik oleh peserta. Simpulan dari kegiatan ini adalah pengajaran ini memberikan manfaat adanya peningkatan pemahaman guru mengenai materi perkembangan manusia, sehingga dapat disarankan untuk dilaksanakan secara rutin dan bergiliran kepada guru-guru yang belum mendapatkan kesempatan untuk mengikutinya.
\end{abstract}

Kata kunci- perkembangan, kompetensi, kognitif, motivasi, guru.

Abstract-Teachers have important roles in education system, so they must improve their competence. One of the institutions concerns about improving teacher competence is ACSI (Association of Christian Schools International). ACSI in collaboration with Lecturers from the Faculty of Psychology,
Maranatha Christian University, organizes teaching Human Development for Christian teachers in Indonesia. The purpose of this teaching is to increase teachers' understanding about Human Development, included development of physics-motor, cognitive, moral, spiritual, memory, learning, motivation and early child education. So that they can apply it in teaching students. The method used is using 8 learning videos that have been prepared by instructor. Participants are 26 teachers from several cities in Indonesia. Participants must watch that video on three weeks. After that, they have to do assigned tasks. On 22 and 29 May 2021, an online face-to-face meeting with zoom media was held, participants and instructors have met, with question and answer activities and discussions about topic that had been presented. After that meeting, an evaluation is carried out through the distribution of questionnaires. The results of the evaluation are that teacher's understanding of human development has increased. Evaluation about the implementation also rated very good by most of participants The conclusion of this activity is that this teaching provides the benefit of increasing teachers' understanding of human development, so it can be recommended to be carried out regularly and take turns to teachers who have not had the opportunity to follow it.

Keywords-development, competency, cognitive, motivation, teacher

\section{PENDAhUluan}

Guru adalah salah satu komponen penting dalam sistem Pendidikan, di samping komponen lainnya, seperti siswa, proses belajar, proses didaktik, media dan proses belajar mengajar itu sendiri. Kompetensi yang perlu dimiliki oleh guru menurut Undang- undang No 14, tahun 2005, tentang guru dan dosen adalah kompetensi pedagogik, kompetensi kepribadian, kompetensi sosial, dan kompetensi professional. Seorang guru perlu senantiasa meningkatkan kompetensinya, agar dapat menjalankan profesinya secara profesional, dan bermanfaat bagi peserta didiknya.

ACSI Indonesia adalah organisasi pendidikan nonprofit,khususnya bagi pendidik Kristen, yang bertujuan 
untuk memperlengkapi banyak sekolah-sekolah Kristen dan pendidik Kristen, termasuk anggota Yayasan Pendidikan Kristen di Indonesia, dengan materi-materi yang bermanfaat untuk meningkatkan kompetensi mereka. Salah satu sasarannya adalah kompetensi pedagogik. Kompetensi Pedagogik adalah kemampuan pemahaman terhadap peserta didik, perancangan dan pelaksanaan pembelajaran, evaluasi hasil belajar, dan pengembangan peserta didik untuk mengaktualisasikan berbagai potensi yang dimilikinya.

Pelatihan Christian Educator Certification Cycle XVI dilakukan ACSI Indonesia dalam mengembangkan kompetensi guru-guru Kristen, terutama dalam materi mengenai perkembangan fisik-motorik, kepribadian, kognitif, spiritual, moral, motivasi belajar siswa dan pemrosesan belajar serta mengingat dalam diri siswa, dan Pendidikan anak usia dini. ACSI menjalin kerja sama dengan Fakultas Psikologi Universitas Kristen Maranatha, untuk mengadakan kegiatan pengembangan kompetensi tersebut. Kegiatan diselenggarakan oleh ACSI berikut fasilitas dan perlengkapannya, seperti Google Class Room, Zoom, upload materi ke Youtube Channel ACSI. Sementara narasumbernya adalah dosen Fakultas Psikologi Universitas Kristen Maranatha, dan materi daring dipersiapkan oleh narasumber dalam bentuk 8 video pembelajaran. Bagi dosen Fakultas Psikologi Universitas Kristen Maranatha, kegiatan ini sekaligus merupakan pelaksanaan Tridharma Perguruan Tinggi, yaitu pengabdian kepada masyarakat.

Identifikasi masalah dalam pengabdian masyarakat ini adalah apakah pengajaran materi perkembangan manusia dapat meningkatkan pemahaman guru-guru sekolah Kristen. Tujuan diadakannya kegiatan ini adalah untuk menambah pemahaman guru mengenai materi perkembangan manusia, agar mereka dapat menerapkannya saat mengajar di tempat masing-masing. Manfaat yang diperoleh dari kegiatan ini adalah guru-guru mengalami peningkatan pemahaman mengenai perkembangan manusia, sehingga saat menyusun materi pembelajaran, aktivitas, dan alat peraga, serta saat menghadapi siswa, mereka dapat menerapkan pemahaman yang telah mereka peroleh.

Agar tujuan kegiatan dapat tercapai,naras umber menyiapkan materi yang diminta oleh ACSI untuk diajarkan kepada para guru, mencakup perkembangan fisikmotorik, kognitif dan kemampuan kognitif, kepribadian (mencakup social emosi), moral, spiritual, proses belajar dan mengingat, motivasi, serta Pendidikan Anak Usia Dini (PAUD). Dasar teori yang dipergunakan adalah perkembangan manusia, dari berbagai literatur.

Menurut Woolfolk (2016), manusia berkembang mengikuti prinsip : manusia berkembang dalam kecepatan yang berbeda-beda, perkembangan itu bertahap dan teratur serta terjadi sedikit demi sedikit [1]. Informasi tentang perkembangan seseorang, sejak prenatal sampai saat dia menjadi siswa, sangat penting untuk diketahui guru. Dengan mengetahui informasi tersebut, guru dapat mengidentifikasi problem sepanjang perkembangan anak, dan dapat merancang program intervensi yang tepat untuk anak.

Perkembangan fisik yang diajarkan dalam materi ini mencakup juga perkembangan otak, karena perkembangan otak pada masa kanak-kanak sangat pesat dan perlu mendapatkan stimulasi dari lingkungan [2]. Pada masa kanak-kanak, sampai usia 3-15 tahun, terjadi ledakan perkembangan yang sangat cepat [3], sehingga penting sekali bagi guru memahami hal ini dan dapat memberikan stimulasi yang tepat saat mengajar siswanya.

Perkembangan fisik berkembang pesat saat usia 2-6 tahun, dan berkembang secara konsisten di usia 6-12 tahun. Selain itu, perkembangan motorik tidak kalah pentingnya. Aktivitas fisik pada masa kanak-kanak sangat penting, untuk mengkoordinasikan gerakan tubuh, mengembangkan ketrampilan motorik kasar dan halus yang akan menjadi dasar bagi aktivitas anak di sekolah. Jika kondisi otak, fisik dan motorik anak berkembang dengan sebagaimana mestinya, kesiapan anak untuk mengikuti proses belajar di sekolah juga menjadi lebih optimal.

Perkembangan kognitif adalah proses penting untuk mendapatkan pengetahuan. Jean Piaget adalah seorang tokoh perkembangan kognitif yang menjelaskan tahapan perkembangan kognitif [1]. Tiap tahapan memiliki karakteristik sendiri, yang menunjukkan bagaimana anak membangun pengetahuannya. Piaget berpendapat bahwa anak adalah individu yang aktif membangun pemahaman tentang dunia [2], yang diperolehnya melalui aktivitas mereka (asimilasi, akomodasi, dan organisasi). Pemahaman mengenai karakteristik tahap perkembangan kognitif anak penting untuk memberikan stimulasi sesuai tahap perkembangannya, dan tidak memaksakan anak mencapai level yang lebih tinggi.

Tokoh lain dalam perkembangan kognitif adalah Vigotsky yang terkenal dengan teori sosiokulturalnya [4]. Menurut Vigotsky, proses kognitif dapat berkembang melalui interaksi sosial. Artinya, meskipun anak aktif membangun pengetahuannya sendiri, interaksi sosial dengan orang yang lebih ahli dapat menstimulasi pengetahuan anak, Anak bisa mengembangkan konsep yang lebih sistematis, logis dan rasional akibat dari percakapan dengan orang yang lebih ahli. Perkembangan Bahasa anak merupakan hal penting dalam perkembangan kognitif. Sumber perkembangan literasi anak adalah stimulasi dari orang tua dan guru dalam mendorong perkembangan anak. Pemahaman mengenai teori Vigotsky ini akan membantu guru lebih menyadari perannya sebagai orang yang lebih ahli yang berinteraksi dengan anak, yang dapat menstimulasi siswa membangun pengetahuannya sendiri melalui dialog [4].

Kemampuan kognitif dapat diukur, dengan menggunakan 
tes tertentu [1]. Oleh sebab itu dikenal istilah tes prestasi dan tes inteligensi. Kemampuan kognitif dapat berkembang dengan peranan faktor bawaan dan lingkungan. Faktor bawaan misalnya faktor genetik, herediter, namun penelitian Ardila et al (2011) menyatakan bahwa jenis kelamin tidak memberikan perbedaan pada kemampuan kognitif [5]. Faktor lingkungan misalnya pola asuh, stimulasi dari sekolah dan rumah. Guru perlu memahami hal ini. Lingkungan pendidikan di sekolah perlu dikembangkan secara positif, agar memungkinkan terciptanya kondisi yang menguntungkan untuk mengoptimalkan potensi yang dimiliki seseorang.

Konsep lain dari kemampuan kognitif adalah multiple intelligences dari Howard Gardner. Menurut Gardner, semua anak memiliki multiple intelligences, sehingga sekolah perlu menyediakan sarana untuk menstimulasi perkembangan kecerdasan tersebut [1].

Guru juga perlu memahami perkembangan kepribadian anak. Tahapan perkembangan Erikson [6] [3], menjelaskan mengenai pentingnya anak melewati krisis di tiap tahap perkembangan psikososialnya, terutama tahap trust $v s$ mistrust, sampai tahap identity achieve vs identity diffusion. Tahapan tersebut ada pada usia siswa PAUD sampai SMA. Dengan memahami tahapan krisis yang sedang dialami siswa yang diajarnya, guru dapat memberikan dorongan untuk siswa berkembang ke arah sisi yang positif, agar dapat menjadi dasar bagi perkembangan tahap selanjutnya.

Guru juga perlu memahami bagaimana remaja bergumul untuk mencapai identitas dirinya, mengembangkan konsep diri dan keberhargaan diri yang positif. Karakteristik yang khas pada remaja, yaitu emosi yang berfluktuasi sejalan dengan perkembangan hormonnya, juga perlu diketahui oleh guru, sehingga guru bisa membantu remaja dalam membangun kecerdasan emosinya. [7]

Perkembangan moral seseorang terkait dengan perkembangan kognitifnya. Kohlberg mengemukakan tahapan moral reasoning [1]. Memahami tahapan moral reasoning akan membantu guru dalam memahami alasan di balik tindakan siswa.

Tahapan perkembangan spiritual siswa juga perlu dipahami oleh guru sekolah Kristen. Teori yang dipakai untuk perkembangan spiritual adalah faith development dari Fowler (1991). Fowler memandang perkembangan iman sebagai universal, mengikuti hirarki dan berurutan. Menurut Fowler, seseorang datang pada aktivitas 'beriman' melalui komunitasnya [8]. Bagi anak-anak, komunitas itu pada awalnya orang tua, makin meluas ke guru, pendeta, dan akhirnya komunitas orang percaya yang berkomitmen. Oleh sebab itu, memperkenalkan Kristus kepada anak-anak dapat dilakukan melalui aktivitas religious, misalnya membaca Alkitab, berdoa, ke gereja/sekolah minggu, persekutuan keluarga, buku dan majalah, radio dan video, pendeta/pembina rohani, music gerejawi, acara khusus, aktivitas-aktivitas/games. Selain itu, kebiasaan-kebiasaan yang dibangun oleh sekolah- sekolah Kristen, seperti berdoa, renungan, retreat atau seminar-seminar kerohanian juga dapat membangun aspek spiritual siswa. Tidak kalah pentingnya adalah keteladanan guru dan memperkenalkan iman Kristiani melalui percakapan sehari-hari saat guru menyampaikan materi dengan penuh kasih dan kesabaran, atau kata-kata yang mengingatkan akan kebesaran Tuhan dalam kehidupan pribadi siswa.

Proses belajar siswa dan proses mengingat juga perlu dipahami oleh guru. Belajar adalah perubahan perilaku yang relatif menetap sebagai hasil pengalaman atau latihan (Woolfolk, 2016). Teori belajar yang diajarkan adalah teori behavior view, social cognitive view dan cognitive view. [1]

Dalam teori behavior view, siswa belajar melalui pengkondisian (pembiasaan terus menerus), teori ini disebut classical conditioning. Kemudian berkembang teori operant conditioning, yaitu bahwa suatu perilaku dapat bertahan apabila diberi reinforcement. Yang penting dalam pengendalian tingkah laku siswa adalah hubungan antara perilaku dan konsekuensi yang mengikutinya, yang disebut reinforcement. Individu aktif melakukan operasi terhadap lingkungannya, maka disebut operant. Setelah itu berkembang teori social learning dari Bandura. Bandura menyebutkan istilah observational learning, yaitu individu dapat belajar dengan mengamati perilaku orang lain dan menirunya (modelling). Dalam belajar diperlukan interaksi antara faktor internal dan eksternal, yang disebut reciprocal determinism (Woolfolk, 2016). Ketiga kekuatan (internal, eksternal dan perilaku belajar) berada dalam interaksi yang constant. Mereka saling memengaruhi dan dipengaruhi. Guru perlu memahami proses belajar siswa dari sudut pandang teori tersebut, agar dapat dimanfaatkan untuk mengembangkan kebiasaan belajar yang efektif. [1]

Teori berikutnya adalah cognitive view (Slavin, 2018) Menurut pandangan ini, belajar adalah perubahan perilaku, dan perilaku yang dimaksudkan adalah pengetahuan. Jadi kalau siswa belajar, yang berubah adalah pengetahuannya. Jika guru mempelajari proses siswa mendapatkan pengetahuannya, menurut pandangan kognitif ini, maka perlu dipelajari juga proses memory. [4]

Memory adalah kemampuan mental untuk menerima, menyimpan, dan memanggil kembali infomasi(pengetahuan dan pengalaman). Informasi masuk melalui panca indra, kemudian masuk ke dalam sensory memory. Jika diberi perhatian akan masuk ke dalam working memory, jika tidak, maka informasi tersebut akan hilang. Kapasitas working memory terbatas, jadi hanya informasi tertentu yang diperhatikan yang akan masuk ke dalam working memory. Dalam belajar, diharapkan informasi masuk ke dalam long term memory, yaitu dengan cara maintenance rehearsal dan elaborative rehearsal. Beberapa metode untuk meningkatkan memory misalnya chunking, metode mnemonic, mempraktikkan konsep kunci, dan latihan menyimpan informasi dengan skema. 
Creative map mnemonic strategy merupakan salah satu metode yang efektif untuk meningkatkan performance belajar [9]. Guru perlu memahami proses ini, agar siswa dapat menyimpan materi dalam long term memory.

Dalam belajar, konsep yang penting adalah motivasi belajar. Guru perlu mempelajari cara memotivasi siswa. Menurut Woolfolk (2016), motivasi adalah proses internal yang mengarahkan, dan mempertahankan tingkah laku sepanjang waktu. Motivasi terkait dengan tujuan. Orang akan termotivasi, bila ia memiliki tujuan yang jelas. Motivasi penting dalam belajar, karena orang yang mau belajar, akan mempelajari apa saja yang diajarkan. [1]

Beberapa teori dalam motivasi adalah behavior theory, humanistic, attribution theory, expectancy theory, learned helplessness dan motivasi intrinsik-ekstrinsik. Dalam behavior theory of motivation, siswa dapat dimotivasi belajar melalui prinsip-prinsip dalam teori ini, yaitu pemberian reward dan punishment, serta pengkondisian yang efektif. Perilaku yang diharapkan, diberi penguatan agar diulang, Sedangkan perilaku yang tidak diharapkan, diberi punishment. Motivasi siswa dapat diperkuat dengan memberikan reinforcement yang tepat sesuai dengan kebutuhan dan goal.

Dalam humanistic theory (Slavin, 2018), dipelajari hirarki kebutuhan manusia menurut Maslow. Motivasi dipandang sebagai dorongan untuk memenuhi kebutuhan. Siswa akan termotivasi didorong oleh kebutuhannya, oleh karena itu penting untuk mengetahui level kebutuhan siswa. Siswa yang lapar, atau secara fisik kurang sehat, akan memiliki sedikit energi untuk belajar. Siswa akan berorientasi pada pemenuhan kebutuhan fisiknya, dan kurang bisa memusatkan perhatian pada pelajaran. Siswa yang merasa kurang dicintai keluarganya, juga akan berorientasi pada usahanya untuk mendapatkan cinta kasih, sehingga tidak fokus pada upaya belajar. Siswa yang merasa dirinya berharga dan mampu belajar, akan lebih termotivasi untuk belajar. Attribution theory adalah penjelasan siswa di balik keberhasilan atau kegagalannya. Sedangkan teori Expectancy $x$ Value mengatakan bahwa kekuatan motivasi seseorang untuk berhasil bergantung pada seberapa besar perkiraannya untuk berhasil dan seberapa penting keberhasilan itu untuk dirinya. [4].

Teori learned helplessness menjelaskan bahwa apapun yang dilakukan akan gagal atau tidak efektif. Helplessness bisa muncul dari reward dan punishment yang tidak konsisten, tidak dapat diprediksi, sehingga timbul pola pikir bahwa apapun yang dilakukannya hanya sedikit yang membuahkan hasil. Untuk mencegah learned helplessness, siswa perlu diberi kesempatan berhasil melalui tahapan kesulitan yang meningkat sedikit demi sedikit. Siswa perlu mengalami berhasil dahulu, baru kesulitan ditingkatkan sedikit, sehingga peluang keberhasilanna juga besar. Selain itu siswa perlu mendapatkan umpan balik langsung, sehingga kesalahan yang dibuat, dapat diperbaiki sedikit demi sedikit, tidak bertumpuk. Jika bertumpuk, siswa akan mengalami kesulitan memperbaikinya, karena terlalu banyak. Siswa perlu mendapatkan ekspektasi yang konsisten dan dimonitor terus menerus [4].

Motivasi intrinsik dan ekstrinsik dibutuhkan dalam belajar. Tidak semua siswa memiliki motivasi intrinsik, sehingga motivasi ekstrinsik tetap dibutuhkan. Guru perlu bisa memotivasi siswa baik secara intrinsik dan ekstrinsik.

Untuk Pendidikan Anak Usia Dini, guru perlu memahami bahwa usia balita merupakan tahap peletakan dasar pertama dalam mengembangkan kemampuan fisik, kognitif, Bahasa, sosial, emosional, konsep diri, disiplin, kemandirian, seni, moral, dan nilai-nilai agama. Salah satu pendekatan dalam PAUD adalah belajar sambil bermain, dan bermain sambil belajar, melalui Gerakan. Gerakan yang dilakukan oleh anak ditujukan untuk mengembangkan ketrampilan motoric, kekuatan, koordinasi dan rasa keseimbangan. Kondisi tersebut akan memengaruhi ketrampilan akademik mereka di kemudian hari, seperti membaca, menulis dan berhitung. [10]

Belajar diawali dari indera, indera menangkap rangsang dari lingkungan, dibawa ke otak, lalu diolah, diberi makna, dan disimpan, lalu suatu kali dibutuhkan akan dipergunakan kembali. Basic academic ability adalah kemampuan dasar yang dibutuhkan untuk kegiatan akademik. Menurut Vallet (1969), basic learning ability mencakup gross motor development, sensory motor integration, perceptual motor skill, language development, conceptual skill dan social skill [10].

Kemampuan dasar tersebut perlu mendapat stimulasi yang optimal dari rumah maupun sekolah, agar anak dapat mengikuti kegiatan akademis dengan efektif. Hanya saja pada masa pandemi COVID-19 ini, banyak kendala dalam melaksanakan stimulasi gerak terhadap basic learning ability siswa. Efektivitas pembelajaran dengan jarak jauh telah diteliti, dan untuk saat ini memang ditemukan masih kurang efektif [11] [12].

\section{PELAKSANAAN KEGIATAN}

Kegiatan Pengabdian Kepada Masyarakat ini tidak bisa dilakukan melalui tatap muka langsung, karena adanya pandemi Covid -19. Oleh sebab itu, kegiatan dilakukan secara daring, dengan memanfaatkan 8 video pembelajaran (asynchronous) dan platform zoom untuk berdiskusi langsung antara narasumber dan peserta (synchronous). Bentuk kegiatan adalah webinar dan pelatihan, yang diikuti oleh guru-guru Kristen dari Bandung, Jakarta, Surabaya, Tangerang, Pasuruan, Pekanbaru, dan Papua.

Pelatihan diberikan dalam bentuk 8 modul video pembelajaran yang disusun oleh pengabdi, dan diunggah penyelenggara, pada minggu keempat April sampai dengan minggu ketiga Mei 2021, ke kanal you tube ACSI Indonesia, mencakup materi: perkembangan fisik, kepribadian, 
kognitif, moral, spiritual, motivasi dan proses belajarmengingat, serta Pendidikan anak usia dini.

Tatap muka daring dilaksanakan tanggal 22 dan 29 Mei $2021 @ 60$ menit. Acara tatap muka daring dihadiri oleh 26 orang guru dari kota Bandung, Jakarta, Surabaya, Tangerang, Pasuruan, Pekanbaru, Papua.

Rincian kegiatan selama acara :

08.00-08.05 Doa oleh penyelenggara

08.05-08.10 Pengarahan dari penyelenggara

08.10-08.50 Pembahasan materi dan diskusi antara Fasilitator dengan peserta

08.50-08.55 Simpulan dari Penyelenggara

08.55-09.00 Doa Penutup

\section{HASIL EVALUASI DAN PEMBAHASAN}

Berikut akan disajikan hasil evaluasi terhadap proses belajar yang terjadi.

\section{A. Hasil Evaluasi}

Jumlah guru yang mengikuti kegiatan ini adalah 26 guru, dan persentase penghayatan guru mengenai peningkatan pemahaman terhadap materi yang diberikan adalah sebagai berikut :

TABEL I

PEMAHAMAN GURU

\begin{tabular}{|l|r|r|r|}
\hline \multirow{2}{*}{ MATERI } & \multicolumn{3}{|c|}{ Peningkatan (dalam \%) } \\
\cline { 2 - 4 } & Meningkat & $\begin{array}{c}\text { Sedikit } \\
\text { Meningkat }\end{array}$ & $\begin{array}{c}\text { Tidak } \\
\text { Meningkat }\end{array}$ \\
\hline Fisik & 100 & 0 & 0 \\
\hline Kepribadian & 100 & 0 & 0 \\
\hline Kognitif & 92 & 8 & 0 \\
\hline Spiritual & 100 & 0 & 0 \\
\hline Moral & 92 & 8 & 0 \\
\hline Belajar- & 90 & 10 & 0 \\
Mengingat & & & 0 \\
\hline Motivasi & 92 & 8 & $\mathbf{0}$ \\
\hline PAUD & 100 & 0 & $\mathbf{4 . 2 5}$ \\
\hline Rata-rata & $\mathbf{9 5 . 7 5}$ & & \\
\hline
\end{tabular}

Dari tabel I tampak bahwa hampir semua guru mengalami adanya peningkatan dalam pemahaman seluruh materi yang diberikan. dan tidak ada yang pemahamannya tidak meningkat.

TABEL II

MEMPERSIAPKAN LEBIH PROFESIONAL

\begin{tabular}{|r|r|r|r|}
\hline \multicolumn{4}{|c|}{ Peningkatan (dalam \%) } \\
\hline Sangat Baik & Baik & Standar & $\begin{array}{c}\text { Bawah } \\
\text { standar }\end{array}$ \\
\hline 73.1 & 23.1 & 3.8 & 0 \\
\hline
\end{tabular}

9. Dari tabel II, terlihat bahwa sebagian besar guru menghayati bahwa program ini sangat baik dalam mempersiapkan mereka untuk lebih profesional dalam menjalankan perannya sebagai guru.

TABEL III

EVALUASI PELAKSANAAN

\begin{tabular}{|c|c|c|c|c|}
\hline \multirow{2}{*}{$\begin{array}{l}\text { MATERI } \\
\text { EVALUASI }\end{array}$} & \multicolumn{4}{|c|}{ Penilaian (dalam \%) } \\
\hline & $\begin{array}{c}\text { Sangat } \\
\text { Baik }\end{array}$ & Baik & Standar & $\begin{array}{l}\text { Bawah } \\
\text { standar }\end{array}$ \\
\hline Isi Modul & 65.4 & 30.8 & 3.8 & 0 \\
\hline Penyajian & 65.4 & 34.6 & 0 & 0 \\
\hline $\begin{array}{l}\text { Penguasaan } \\
\text { materi }\end{array}$ & 92.3 & 7.7 & 0 & 0 \\
\hline $\begin{array}{l}\text { Efektivitas } \\
\text { Waktu }\end{array}$ & 80.8 & 19.2 & 0 & 0 \\
\hline $\begin{array}{l}\text { Integrasi } \\
\text { konsep } \\
\text { Alkitab }\end{array}$ & 80.8 & 19.2 & 0 & 0 \\
\hline $\begin{array}{l}\text { Interaksi } \\
\text { dengan } \\
\text { peserta }\end{array}$ & 96.2 & 3.8 & 0 & 0 \\
\hline $\begin{array}{l}\text { Sensitivitas } \\
\text { terhadap } \\
\text { kebutuhan } \\
\text { peserta }\end{array}$ & 65.4 & 34.6 & 0 & 0 \\
\hline Rata-rata & 78.04 & 21.42 & 0.54 & $\mathbf{0}$ \\
\hline
\end{tabular}

Dari tabel III, dapat dilihat bahwa sebagian besar pelaksanaan kegiatan dinilai sangat baik, dan baik oleh peserta. Sangat sedikit yang dinilai standar, dan tidak ada yang dinilai di bawah standar.

\section{B. Pembahasan Hasil Evaluasi}

Berdasarkan hasil evaluasi yang telah ditampilkan pada tabel I,II dan III, dapat terlihat bahwa pelaksanaan kegiatan pengajaran materi perkembangan manusia untuk guru-guru sekolah Kristen di Indonesia, ternyata dapat meningkatkan pemahaman hampir semua peserta tentang seluruh materi yang diajarkan.

Pada tabel I, jika dilihat rata-rata keseluruhan peningkatan, diperoleh hasil bahwa 95.75 peserta mengalami adanya peningkatan dalam pemahaman materi, lalu 4.25 persen yang mengalami sedikit peningkatan, dan tidak ada yang mengalami tidak adanya peningkatan. Adanya 4.25 persen peserta yang mengalami sedikit peningkatan, diduga berkaitan dengan masukan yang diberikan peserta mengenai terbatasnya waktu untuk bertanya jawab. Pertemuan tatap muka daring yang disediakan panitia adalah 2x 60 menit, dan jumlah waktu tersebut dirasa kurang oleh peserta. Dalam salah satu item kuesioner evaluasi, sebagian peserta mengusulkan penambahan waktu untuk berinteraksi langsung lewat 
zoom, agar lebih banyak pertanyaan bisa dijawab oleh fasilitator.

Pada tabel II, sebagian besar peserta menghayati bahwa program kegiatan ini sangat baik dalam mempersiapkan mereka untuk menjadi lebih profesional sebagai guru. Materi perkembangan manusia memang dipersiapkan untuk meningkatkan pemahaman guru mengenai perkembangan manusia secara utuh, dan diharapkan dapat meningkatkan kompetensi pedagogik guru. Peningkatan kompetensi akan berdampak positif pada profesionalitas mereka Ketika mengajar, materi dan metode dipersiapkan dengan mempertimbangkan aspek perkembangan manusia secara utuh.

Dari tabel III, pelaksanaan kegiatan secara keseluruhan dinilai sangat baik dan baik. Jika dilihat persentase rata-rata secara keseluruhan, maka $78.04 \%$ menilai pelaksanaan sudah sangat baik; dan $21.42 \%$ menilai baik. Hanya $0.54 \%$ menilai standar, dan tidak ada yang menilai di bawah standar.

Aspek yang mendapat penilaian tertinggi adalah interaksi dengan peserta, dan penguasaan materi. Narasumber dinilai sangat baik dalam berinteraksi dengan peserta dan dinilai sangat menguasai materi yang disajikan. Hal ini diperkuat dengan jawaban peserta dalam salah satu item open ended, yang menyatakan bahwa mereka puas dengan penjelasan materi dan jawaban yang diberikan saat interaktif.

Aspek yang mendapat penilaian standar adalah isi modul, meskipun hanya dinilai oleh $0,54 \%$ dari keseluruhan peserta. Aspek ini juga mungkin berkaitan dengan masukan yang diberikan peserta mengenai ditambahnya contohcontoh kasus saat menjelaskan. Tentunya masukan ini berkaitan erat dengan peningkatan kualitas isi modul, agar tidak hanya sekedar standar, namun juga prima/unggul.

\section{KESIMPULAN}

Dari uraian yang telah dipaparkan, maka dapat ditarik kesimpulan bahwa secara keseluruhan modul perkembangan manusia yang telah diajarkan, dinilai meningkatkan pemahaman guru, dan mempersiapkan guru menjadi lebih professional. Pelaksanaan kegiatan juga dinilai sudah sangat baik, hanya saja beberapa kelemahan yang perlu menjadi perhatian adalah kurangnya waktu interaktif.

Pelaksanaan kegiatan ini dapat diusulkan untuk diikuti oleh guru-guru lain yang belum mengikuti program ini, sehingga makin banyak guru yang mendapatkan pemahaman mengenai perkembangan manusia.

\section{UCAPAN TERIMA KASIH}

Ucapan terima kasih yang sebesar-besarnya diberikan kepada Universitas Kristen Maranatha dan Association Christian School Indonesia, atas kesempatan mengabdi yang telah diberikan kepada kami.

\section{DAFTAR PUSTAKA}

[1] A. Woolfolk, Educational Psychology, London: Pearson, 2016.

[2] J. W. Santrock, Life Span Development 13th, New York: Mc Graw-Hill, 2011.

[3] J. W. Santrock, Child Development 15th, New York: Mc Graw Hill, 2020.

[4] R. Slavin, Educational Psychology : Theory and Practice, New York: Pearson, 2018.

[5] Alfredo Ardila, Monica Roselli, Esmeralda Matute \& Olga Inozemtseva, "Gender Differences in Cognitive Development," Developmental Psychology, vol. 47, no. 4, pp. 984-990, 2011.

[6] Papalia, Diane E. \& Feldman, Ruth Duskin, Experience Human Development 12th, New York: Mc Graw Hill, 2014.

[7] J. W.Santrock, Adolescence, New York: Mc Graw Hill, 2015.

[8] J. Fowler, "Stages in faith consciousness.," New directions for Child and Adolescent Development, vol. 52, pp. 27-45, 1991.

[9] Yu-Hsiu Liao, Wei-Chieh Kung\&HsuehChih Chen, "Testing the effectiveness of creative map mnemonic," Instructional Science, vol. 47, pp. 589-608, 2019.

[10] R. E. Vallet, Programming Learning Disabilities, California: Fearon Publishers, 1969.

[11] Nurdin \& La Ode Anhusadar, "Efektivitas Pembelajaran Online Pendidik PAUD di tengah Pandemi COVID-19," Jurnal Obsesi : Jurnal Pendidikan Anak Usia Dini, vol. 5, no. 1, pp. 686-697, 2021. 
[12] Nurkolis \& Muhdi, "Keefektifan Kebijakan e-learning berbasis sosial media pada PAUD di masa Pandemi COVID-19," Jurnal Obsesi : Jurnal Pendidikan Anak Usia Dini, vol. 5, no. 1, pp. 212-228, 2020.

[13] [Online]. 